\title{
Snow cover and soil moisture controls of freeze-thaw-related soil gas fluxes from a typical semi-arid grassland soil: a laboratory experiment
}

\author{
Xing Wu • Nicolas Brüggemann • Klaus Butterbach-Bahl • \\ Bojie Fu • Guohua Liu
}

Received: 18 June 2013 / Revised: 1 August 2013 / Accepted: 26 August 2013 / Published online: 13 September 2013

(C) Springer-Verlag Berlin Heidelberg 2013

\begin{abstract}
In situ field measurements as well as targeted laboratory studies have shown that freeze-thaw cycles (FTCs) affect soil trace gas fluxes. However, most of past laboratory studies adjusted soil moisture before soil freezing, thereby neglecting that snow cover or water from melting snow may modify effects of FTCs on soil trace gas fluxes. In the present laboratory study with a typical semi-arid grassland soil, three different soil moisture levels (32\%, $41 \%$, and $50 \%$ WFPS) were established (a) prior to soil freezing or (b) by adding fresh snow to the soil surface after freezing to simulate field conditions and the effect of the melting snow on $\mathrm{CO}_{2}, \mathrm{CH}_{4}$, and $\mathrm{N}_{2} \mathrm{O}$ fluxes during FTCs more realistically. Our results showed that adjusting soil moisture by watering before soil freezing resulted in significantly different cumulative fluxes of $\mathrm{CH}_{4}, \mathrm{CO}_{2}$, and $\mathrm{N}_{2} \mathrm{O}$ throughout three FTCs as compared to the snow cover treatment, especially at a relatively high soil moisture level of $50 \%$ WFPS. An increase of $\mathrm{N}_{2} \mathrm{O}$ emissions was observed during thawing for both treatments. However, in the watering treatment, this increase was highest in the first
\end{abstract}

$\mathrm{X} . \mathrm{Wu}(\bowtie) \cdot \mathrm{B} . \mathrm{Fu} \cdot \mathrm{G} . \mathrm{Liu}$

State Key Laboratory of Urban and Regional Ecology, Research Center for Eco-environmental Sciences (RCEES), Chinese Academy of Sciences, P.O. Box 2871, 100085 Beijing, China

e-mail: xingwu@rcees.ac.cn

X. Wu $\cdot$ K. Butterbach-Bahl

Institute for Meteorology and Climate Research, Atmospheric Environmental Research (IMK-IFU), Karlsruhe Institute of Technology, Kreuzeckbahnstrasse 19, Garmisch-Partenkirchen, Germany

\section{N. Brüggemann}

Agrosphere Institute (IBG-3), Forschungszentrum Jülich GmbH, Leo-Brandt-Strasse, 52425 Jülich, Germany thawing cycle and decreased in successive cycles, while in the snow cover treatment, a repetition of the FTCs resulted in a further increase of $\mathrm{N}_{2} \mathrm{O}$ emissions. These differences might be partly due to the different soil water dynamics during FTCs in the two treatments. $\mathrm{CO}_{2}$ emissions were a function of soil moisture, with emissions being largest at $50 \%$ WFPS and smallest at $32 \%$ WFPS. The largest $\mathrm{N}_{2} \mathrm{O}$ emissions were observed at WFPS values around $50 \%$, whereas there were only small or negligible $\mathrm{N}_{2} \mathrm{O}$ emissions from soil with relatively low soil water content, which indicates that a threshold value of soil moisture might exist that triggers $\mathrm{N}_{2} \mathrm{O}$ peaks during thawing.

Keywords Snow cover - Soil moisture $\cdot$ Freeze-thaw cycles Trace gases $\cdot$ Semi-arid grassland

\section{Introduction}

Soil freeze-thaw cycles (FTCs) occur regularly in regions at mid- to high latitude as well as high altitude. Increased $\mathrm{CO}_{2}$, $\mathrm{N}_{2} \mathrm{O}$ emissions and $\mathrm{CH}_{4}$ uptakes have been frequently reported during soil freezing and thawing, both in laboratory (e.g., Koponen and Martikainen 2004; Goldberg et al. 2008; Wu et al. 2010a; Yao et al. 2010) and field experiments (e.g., Papen and Butterbach-Bahl 1999; Groffman et al. 2006; Holst et al. 2008; Goldberg et al. 2010; Wolf et al. 2010). Moreover, some studies indicated that more than $50-70 \%$ of the annual $\mathrm{N}_{2} \mathrm{O}$ emissions may be ascribed to freeze-thaw events (Goldberg et al. 2010; Wolf et al. 2010; Wu et al. 2010b). Several processes have been discussed to cause the freeze-thaw-related stimulation of soil trace gas fluxes: physical release of gases produced in unfrozen parts of the soil and 
accumulated below the frozen soil layer (Teepe et al. 2001; Goldberg et al. 2010) and/or enhanced microbial metabolism by substrate supply (Papen and Butterbach-Bahl 1999; Ludwig et al. 2004; Groffman et al. 2006; De Bruijn et al. 2009). However, there are still many uncertainties in our understanding of the mechanisms involved in these increased fluxes (Matzner and Borken 2008; Goldberg et al. 2010; Kim et al. 2012).

One of the major uncertainties with respect to the relevance of FTCs for soil trace gas fluxes arises from experimental artifacts (Henry 2007; Goldberg et al. 2010). For example, most laboratory studies under controlled conditions did not include snow cover in their experimental designs, and soil moisture levels were usually adjusted before soil freezing (Priemé and Christensen 2001; Teepe et al. 2004; Wu et al. 2010a). However, snow cover has been reported to be particularly important for $\mathrm{C}$ and $\mathrm{N}$ trace gas fluxes during soil freezing and thawing (Groffman et al. 2006, 2011), since it can not only exert strong control on the dynamics of soil temperature and moisture (Buckeridge and Grogan 2010) but also significantly affect soil $\mathrm{C}$ and $\mathrm{N}$ turnover and soil microbial community structure and function (Feng et al. 2007; Groffman et al. 2011). Thus, the effects of snow cover and water from melting snow should be implemented in FTC studies.

Soil moisture has been identified as one of the crucial drivers of temporal variability of soil $\mathrm{C}$ and $\mathrm{N}$ trace gas fluxes on hourly to interannual timescales (Papen and ButterbachBahl 1999; Borken et al. 2006; Wolf et al. 2010; Kern et al. 2012). Besides its function as a transport medium for microbial substrates, such as $\mathrm{NO}_{3}{ }^{-}$and $\mathrm{NH}_{4}{ }^{+}$, soil water influences gas diffusion in the soil profile and thus also $\mathrm{O}_{2}$ availability and supply for microbial processes. It thereby determines whether aerobic processes such as nitrification or anaerobic processes such as denitrification prevail within the soil (Schindlbacher et al. 2004; Wu et al. 2010b; Wolf et al. 2011). Although the effects of soil moisture on trace gas fluxes have been well documented, there is little information on the effect of soil water content during freeze-thaw periods (Teepe et al. 2004; Kim et al. 2012). The results of Teepe et al. (2004) showed that $\mathrm{N}_{2} \mathrm{O}$ emissions during thawing increased with an increase of water-filled pore space (WFPS) from $42 \%$ to $64 \%$, but decreased at $76 \%$ WFPS. Li et al. (2012) reported that the non-significant $\mathrm{N}_{2} \mathrm{O}$ emissions during the spring soil thawing period in an alpine grassland might have been partly due to the relatively low soil water content found at their study sites $(<30 \%)$. Therefore, which range of soil moisture could induce significant changes of and/or result in maximum trace gas fluxes during soil FTCs is still unclear.

In this laboratory study, we evaluated the effects of snow cover and soil moisture on $\mathrm{CO}_{2}, \mathrm{~N}_{2} \mathrm{O}$, and $\mathrm{CH}_{4}$ fluxes from a typical semi-arid grassland soil subjected to several subsequent FTCs. The following hypotheses were tested: (1) snow cover plays a key role in governing GHG fluxes during FTCs; (2) the enhancement of $\mathrm{N}_{2} \mathrm{O}$ emissions by FTCs might only become significant if the soil moisture lies above a certain threshold.

\section{Materials and methods}

Soil sampling and analysis

For the experiments, undisturbed soil cores $(15 \mathrm{~cm}$ inner diameter, $40 \mathrm{~cm}$ height) were taken from typical semi-arid grassland in Inner Mongolia, China $\left(43^{\circ} 58^{\prime} \mathrm{N}, 116^{\circ} 43^{\prime} \mathrm{E}\right)$. Annual mean air temperature in this region was $0.7^{\circ} \mathrm{C}$ during $1982-2005$, with the maximum monthly mean of $19.0^{\circ} \mathrm{C}$ in July and the minimum of $-21.1^{\circ} \mathrm{C}$ in January. The mean annual precipitation of approximately $335 \mathrm{~mm}(166-507 \mathrm{~mm})$ is distributed unevenly among seasons, with $60-80 \%$ falling as rain primarily between June and August (Wu et al. 2010a). Topsoil generally starts to freeze in late October and thaws in April. Earlier field (Holst et al. 2008; Wolf et al. 2010) and laboratory (Wu et al. 2010a; Yao et al. 2010) studies in this region showed that soil-atmosphere exchange of trace gases were significantly affected by soil FTCs. The soil $\mathrm{pH}$ and bulk density in the $0-20-\mathrm{cm}$ soil layer were 6.62 and $1.37 \mathrm{~g} \mathrm{~cm}^{-3}$, respectively. The soil consisted of $64.5 \%$ sand, $21.4 \%$ silt, and $14.1 \%$ clay with a soil organic carbon (SOC) of $18.4 \mathrm{~g} \mathrm{~kg}^{-1}$. Initial soil WFPS, $\mathrm{NO}_{3}^{-}{ }^{-} \mathrm{N}$, and $\mathrm{NH}_{4}{ }^{+}-\mathrm{N}$ contents in the $0-20-\mathrm{cm}$ layer at soil sampling were $16.2 \%$, $1.93 \mathrm{mg} \mathrm{kg}^{-1}$, and $2.15 \mathrm{mg} \mathrm{kg}^{-1}$, respectively.

Soil core sampling was done in July 2009 by using PVC tubes (15 cm inner diameter, $50 \mathrm{~cm}$ height), which insured $10 \mathrm{~cm}$ of headspace left above the intact soil cores after sampling. The PVC tubes were carefully driven into the soil with simultaneous cutting and removal of surrounding soil, thereby reducing disturbance and compaction of the soil inside the tubes to a minimum. Collected soil cores (18 in total) were transported to the laboratory and stored at a constant temperature of $+4{ }^{\circ} \mathrm{C}$ before the freeze-thaw experiments. In order to keep conditions as natural as possible and to avoid emission losses, we did not disturb the soil by sieving or other treatments throughout the whole incubation period. However, soil $\mathrm{NO}_{3}{ }^{-}$and $\mathrm{NH}_{4}{ }^{+}$concentrations, bulk density, WFPS, and microbial biomass $\mathrm{C}$ and $\mathrm{N}$ from four different depths were analyzed at the end of the incubation experiments (Table 1).

Gravimetric soil water content was determined by drying the soil samples at $105{ }^{\circ} \mathrm{C}$ for $24 \mathrm{~h}$. Soil bulk densities were determined gravimetrically, and $\mathrm{pH}$ in a water suspension $(1: 2.5 w: w)$. Soil WFPS was calculated from bulk density and volumetric soil moisture content using a particle density of $2.65 \mathrm{~g} \mathrm{~cm}^{-3}$. The SOC content was analyzed with an automated $\mathrm{C}$ and $\mathrm{N}$ analyzer (Elementar, Hanau, Germany). Soil $\mathrm{NO}_{3}{ }^{-}$and $\mathrm{NH}_{4}{ }^{+}$concentrations were determined photo- 
Table 1 Soil bulk density, inorganic N, microbial biomass C/N, and water-filled pore space (WFPS) at different soil depths for two treatments after the incubation experiment (mean $\pm \mathrm{SE}, N=9$ )

\begin{tabular}{|c|c|c|c|c|c|c|c|c|c|}
\hline \multirow[t]{2}{*}{ Treatment } & \multirow{2}{*}{$\begin{array}{l}\text { Soil } \\
\text { depth } \\
(\mathrm{cm})\end{array}$} & \multirow{2}{*}{$\begin{array}{l}\text { Bulk density } \\
\left(\mathrm{g} \mathrm{cm}^{-3}\right)\end{array}$} & \multirow{2}{*}{$\begin{array}{l}\mathrm{NH}_{4}{ }^{+}-\mathrm{N} \\
\left(\mathrm{mg} \mathrm{kg}^{-1}\right. \\
\mathrm{SDW})\end{array}$} & \multirow{2}{*}{$\begin{array}{l}\mathrm{NO}_{3}{ }^{-}-\mathrm{N} \\
\left(\mathrm{mg} \mathrm{kg}^{-1}\right. \\
\mathrm{SDW})\end{array}$} & \multirow{2}{*}{$\begin{array}{l}\text { Biomass C } \\
\left(\mathrm{mg} \mathrm{C}^{-1}\right. \\
\text { SDW) }\end{array}$} & \multirow{2}{*}{$\begin{array}{l}\text { Biomass N } \\
\left(\mu g \mathrm{~g}^{-1}\right. \\
\text { SDW) }\end{array}$} & \multicolumn{3}{|l|}{ WFPS (\%) } \\
\hline & & & & & & & $\mathrm{R} 1$ & $\mathrm{R} 2$ & $\mathrm{R} 3$ \\
\hline \multirow[t]{4}{*}{ Watering } & $0-7.5$ & $1.25 \pm 0.05 \mathrm{~A}$ & $2.9 \pm 1.4 \mathrm{~A}$ & $33.4 \pm 7.4 \mathrm{~A}$ & $0.22 \pm 0.02 \mathrm{~A}$ & $50.4 \pm 2.2 \mathrm{~A}$ & $35.3 \pm 1.2 \mathrm{Aa}$ & $42.3 \pm 1.4 \mathrm{Ab}$ & $50.0 \pm 1.5 \mathrm{Ac}$ \\
\hline & $7.5-15$ & $1.43 \pm 0.02 \mathrm{~B}$ & $0.6 \pm 0.3 \mathrm{~B}$ & $10.8 \pm 0.7 \mathrm{~B}$ & $0.11 \pm 0.02 \mathrm{~B}$ & $27.5 \pm 1.8 \mathrm{~B}$ & $30.7 \pm 1.3 \mathrm{Aa}$ & $38.0 \pm 3.9 \mathrm{ABb}$ & $44.7 \pm 2.5 \mathrm{Ac}$ \\
\hline & $15-25$ & $1.51 \pm 0.02 \mathrm{BC}$ & $1.0 \pm 0.4 \mathrm{~B}$ & $8.6 \pm 0.4 \mathrm{~B}$ & $0.06 \pm 0.01 \mathrm{C}$ & $17.7 \pm 0.6 \mathrm{C}$ & $27.9 \pm 2.3 \mathrm{Aa}$ & $30.7 \pm 0.9 \mathrm{Bab}$ & $36.8 \pm 2.2 \mathrm{Bb}$ \\
\hline & $25-35$ & $1.56 \pm 0.03 \mathrm{C}$ & $0.8 \pm 0.2 \mathrm{~B}$ & $5.9 \pm 0.8 \mathrm{~B}$ & $0.04 \pm 0.01 \mathrm{C}$ & $11.4 \pm 1.2 \mathrm{D}$ & $16.2 \pm 5.1 \mathrm{Ba}$ & $33.6 \pm 2.9 \mathrm{Bb}$ & $35.9 \pm 2.1 \mathrm{Bb}$ \\
\hline \multirow{4}{*}{$\begin{array}{l}\text { Snow } \\
\text { cover }\end{array}$} & $0-7.5$ & $1.26 \pm 0.06 \mathrm{~A}$ & $1.8 \pm 0.1 \mathrm{~A}$ & $13.4 \pm 1.8 \mathrm{~A}$ & $0.26 \pm 0.02 \mathrm{~A}$ & $36.1 \pm 1.3 \mathrm{~A}$ & $30.1 \pm 2.5 \mathrm{Aa}$ & $40.3 \pm 2.2 \mathrm{Ab}$ & $51.3 \pm 0.2 \mathrm{Ac}$ \\
\hline & $7.5-15$ & $1.35 \pm 0.03 \mathrm{AB}$ & $1.2 \pm 0.4 \mathrm{~A}$ & $9.6 \pm 1.2 \mathrm{~B}$ & $0.16 \pm 0.01 \mathrm{~B}$ & $17.1 \pm 1.5 \mathrm{~B}$ & $27.6 \pm 2.2 \mathrm{Aa}$ & $38.3 \pm 3.2 \mathrm{Ab}$ & $42.3 \pm 1.8 \mathrm{Ab}$ \\
\hline & $15-25$ & $1.44 \pm 0.04 \mathrm{~B}$ & $1.3 \pm 0.2 \mathrm{~A}$ & $8.7 \pm 0.6 \mathrm{~B}$ & $0.11 \pm 0.01 \mathrm{C}$ & $11.5 \pm 0.7 \mathrm{C}$ & $28.4 \pm 0.2 \mathrm{Aa}$ & $32.0 \pm 0.6 \mathrm{Ba}$ & $42.6 \pm 5.1 \mathrm{Ab}$ \\
\hline & $25-35$ & $1.54 \pm 0.03 \mathrm{C}$ & $1.1 \pm 0.2 \mathrm{~A}$ & $7.3 \pm 1.2 \mathrm{~B}$ & $0.07 \pm 0.01 \mathrm{D}$ & $7.0 \pm 0.9 \mathrm{D}$ & $25.4 \pm 1.6 \mathrm{Aa}$ & $32.7 \pm 2.6 \mathrm{Bb}$ & $41.0 \pm 0.3 \mathrm{Ac}$ \\
\hline
\end{tabular}

Uppercase letters indicate significant differences among different soil depths; lowercase letters indicate significant differences of WFPS among different simulated soil moisture levels $(P<0.05$, one-way ANOVA, LSD)

metrically after extracting the soil with $1 \mathrm{M} \mathrm{KCl}$ solution (1:2 $w: w)$ for $1 \mathrm{~h}$. Microbial biomass $\mathrm{C}$ and $\mathrm{N}$ in soil samples was measured using the chloroform fumigation-extraction method (Vance et al. 1987; Wu et al. 2010a).

\section{Freeze-thaw experiments}

All experiments with the intact soil cores were performed in an incubator (Thermo Electron LED BK 700, GmbH, Germany) to maintain constant temperature levels and to simulate FTCs. The air within the incubator was exchanged with outside air by a pump to avoid gas accumulation and temperature heterogeneities. To reduce experimental artifacts, the sidewalls and the bottom of the soil cores were insulated by 2.0 -cm-thick insulating material (Armaflex, Armacell GmbH, Münster, Germany).

We started the incubation and measurements at a temperature of $5{ }^{\circ} \mathrm{C}$ for 3 days to ensure that fluxes were constant. Subsequently, $25 \mathrm{~mm}$ of artificial rain (standard rain mixture: $11 \mathrm{mg} \mathrm{CaCl} 2,24.4 \mathrm{mg} \mathrm{KCl}$, and $18.6 \mathrm{mg} \mathrm{Na}_{2} \mathrm{SO}_{4}$ in $1,000 \mathrm{ml}$ of deionized water; Breuer et al. 2002) were applied to all 18 soil cores to reactivate soil microbial activity, followed by measurement of trace gas fluxes/vertical concentration profiles until the peak response to the watering declined and fluxes stabilized again at a constant level. After this dry-wet transition, the 18 soil cores were equally split into two groups. The first group of nine cores was again separated into three subgroups of three cores each. The soil moisture of the first subgroup was kept constant (R1), whereas the second and third subgroup received additional $20 \mathrm{~mm}$ (R2) and $40 \mathrm{~mm}$ (R3) rainfall, respectively, on day 11 (before soil freezing). Thus, three different soil moisture levels were created and maintained throughout the following experimental period by daily reweighing of the cores and replacing weight losses with water solution. Watering was carried out at least half an hour before gas sampling to minimize possible gas pulses caused by the watering. In contrast, for the second group of nine cores, the three different soil moisture conditions were established at day 19 by adding fresh snow to the soil surface of the already frozen soil. The amounts of added snow were equal to the water amounts applied in the first group of cores. All the added snow melted during the first thawing phase within 2 days. The average WFPS of the top 0-7.5 $\mathrm{cm}$ soil depth of the three different soil moisture levels were about $32 \%(\mathrm{R} 1), 41 \%$ (R2), and $50 \%$ (R3), respectively (Table 1). Three FTCs were simulated to study the effects of sequential FTCs on soil $\mathrm{CO}_{2}, \mathrm{~N}_{2} \mathrm{O}$, and $\mathrm{CH}_{4}$ fluxes. The temperature in each FTC was set to $-10{ }^{\circ} \mathrm{C}$ for 10 days and then to $+5^{\circ} \mathrm{C}$ for 10 days.

Gas sampling and analysis

$\mathrm{CO}_{2}, \mathrm{~N}_{2} \mathrm{O}$, and $\mathrm{CH}_{4}$ fluxes were determined at daily resolution, while soil profile measurements of these gases at four soil depths $(5,10,20$, and $30 \mathrm{~cm})$ were measured at least twice per week. The fluxes of $\mathrm{CO}_{2}, \mathrm{~N}_{2} \mathrm{O}$, and $\mathrm{CH}_{4}$ were measured using the static chamber method. The PVC tubes (soil cores) were sealed with stainless steel lids, enclosing a headspace of $\sim 1.81$. The lids were equipped with a circulating fan to ensure complete gas mixing of the headspace and with a septum for gas sampling. Five $20-\mathrm{ml}$ gas samples from each chamber headspace were taken with gas-tight syringes at $0,15,30,45$, and $60 \mathrm{~min}$ after closing the lid. The gas samples were immediately analyzed using two gas chromatographs. The first (GC14A, Shimadzu, Kyoto, Japan) was equipped with a flame ionization detector (FID) and an electron capture detector (ECD) for $\mathrm{CH}_{4}$ and $\mathrm{N}_{2} \mathrm{O}$, respectively, and the second (Perkin Elmer, Waltham, MA, USA) had a thermal conductivity detector (TCD) for $\mathrm{CO}_{2}$. To avoid interference of $\mathrm{CO}_{2}$ with the $\mathrm{N}_{2} \mathrm{O}$ analysis, the DN-ascarite method was used (Yao et al. 2010). Fluxes were calculated from the linear increase or decrease in gas concentrations with time within the chambers 
during closure, which showed to be the best approach for calculation of fluxes. In addition, soil air samples were taken from each soil core with stainless steel needles $(1.5 \mathrm{~mm}$ outer diameter, $5 \mathrm{~cm}$ long) near the soil surface and at four different depths during the period of flux measurements. These needles were a side port opening at the end and were inserted into the soil core via four small holes ( $5 \mathrm{~mm}$ diameter), which were sealed by rubber septum to ensure gastight. For each depth, $2 \mathrm{ml}$ of soil air were collected, and the concentration was analyzed as described above.

\section{Statistical analyses}

Statistical analyses were carried out with SPSS 13.0 and SigmaPlot 2000 (SPSS Inc., Chicago, IL, USA). To avoid the interference of gas flux pulses observed as a consequence of the rewetting of dry soil, we used the data after the dry-wet transition to calculate the mean values at different soil moisture and temperature levels during FTCs. Significant differences in trace gas fluxes among different soil moisture levels, temperatures, FTCs, and water treatments were determined using oneway ANOVA and MANOVA analysis.

\section{Results}

$\mathrm{CO}_{2}$ and $\mathrm{CH}_{4}$ fluxes

The average $\mathrm{CO}_{2}$ fluxes from all soil cores before the initial rewetting of the dry soil were relatively low (approximately $10 \mathrm{mg} \mathrm{C} \mathrm{m}^{-2} \mathrm{~h}^{-1}$ ) with no differences between cores finally used for watering and snow cover treatments. Addition of the initial $25 \mathrm{~mm}$ simulated rainfall for reactivating soil microbial activity resulted in a significant increase in $\mathrm{CO}_{2}$ fluxes for all soils, with maximum fluxes of $90.9 \pm 24.5$ and $97.4 \pm 25.5 \mathrm{mg} \mathrm{C} \mathrm{m}^{-2} \mathrm{~h}^{-1}$ in the watering and snow cover treatment, respectively (Fig. 1). For the watering treatment, a significant positive soil moisture effect on $\mathrm{CO}_{2}$ emissions, i.e., increasing emissions with increasing soil moisture, was observed during the second water addition. However, no significant $\mathrm{CO}_{2}$ emission peak was found in the snow cover treatment, even though soils received the same amount of water $(40 \mathrm{~mm})$ due to snow melting, with snow being completely melting at the end of the second day of the first thaw period. The displacement of soil gas was likely responsible for the significant $\mathrm{CO}_{2}$ fluxes upon watering, whereas in the treatment receiving snow, this displacement might occur over the course of $24-48 \mathrm{~h}$ (Fig. 1). During the frost periods, soil $\mathrm{CO}_{2}$ fluxes decreased dramatically in both watering and snow cover treatments, and no significant differences were found among different soil moisture levels (Fig. 2). However, $\mathrm{CO}_{2}$ emissions remained at a low level $\left(<15 \mathrm{mg} \mathrm{C} \mathrm{m}^{-2} \mathrm{~h}^{-1}\right)$ indicating that microbial activity was still present in the frozen soil. $\mathrm{CO}_{2}$ emissions from soils with different soil moisture levels were all significantly enhanced during the first thawing period $(P<$ 0.05 , Fig. 2), but the cumulative fluxes were gradually decreased with successive cycles in both watering and snow cover treatments (Table 2). During the three thawing periods, $\mathrm{CO}_{2}$ emissions were generally higher at higher soil moisture content. The cumulative $\mathrm{CO}_{2}$ fluxes for the watering and snow cover treatments were generally not significantly different, except for the soil moisture level R3 during the first FTC and during the entire three FTCs (Table 2). The two-way ANOVA analysis showed that soil $\mathrm{CO}_{2}$ fluxes were significantly affected by FTCs $(P<0.01)$ at three soil moisture levels, whereas treatment only exhibited significant effects on soil $\mathrm{CO}_{2}$ fluxes at soil moisture level R3 ( $P=0.006$, Table 3).

During most of the investigated period, the soils functioned as a net sink for atmospheric $\mathrm{CH}_{4}$, except for some sporadic weak emissions of $\mathrm{CH}_{4}$ during the frost periods. In contrast to $\mathrm{CO}_{2}$, no significant changes of $\mathrm{CH}_{4}$ flux were observed due to the addition of artificial rain and snow (Fig. 3). $\mathrm{CH}_{4}$ fluxes in the frost periods were substantially reduced as compared to the frost-free periods, especially for the soils in the snow addition treatment. However, all treatments showed a significant increase in soil $\mathrm{CH}_{4}$ uptake activity following thawing $(P<$ 0.05 , Fig. 2), though the increase generally decreased in successive FTCs. Although $\mathrm{CH}_{4}$ uptake generally showed no significant difference among different soil moisture levels during the frost periods, $\mathrm{CH}_{4}$ uptake rates at soil moisture level $\mathrm{R} 1$ were significantly higher than those at R2 and R3 levels during thawing periods $(P<0.05$, Fig. 2$)$. In the watering treatment, the cumulative fluxes of $\mathrm{CH}_{4}$ during three FTCs at soil moisture levels R2 and R3 were significantly higher than those in the snow cover treatment $(P<0.05$, Table 2$)$. However, when all the measurements were analyzed by twoway ANOVA, no significant effects of FTCs, treatment, and their interactions on soil $\mathrm{CH}_{4}$ fluxes were found (Table 3).

\section{$\mathrm{N}_{2} \mathrm{O}$ fluxes}

Similar to $\mathrm{CO}_{2}$, initial rewetting of soil cores with $25 \mathrm{~mm}$ artificial rainfall resulted in an increase in $\mathrm{N}_{2} \mathrm{O}$ emissions for all soils. However, no significant $\mathrm{N}_{2} \mathrm{O}$ emission peak was observed during the second addition of water, neither in the form of artificial rain nor snow (Fig. 4). This different dynamics of $\mathrm{CO}_{2}$ and $\mathrm{N}_{2} \mathrm{O}$ fluxes indicated that the increased $\mathrm{N}_{2} \mathrm{O}$ emissions were not only induced by soil gas displacement but also significantly driven by the stimulation of soil microbial activity via the first $25 \mathrm{~mm}$ wetting event. For R1 and R2 soil moisture levels, the $\mathrm{N}_{2} \mathrm{O}$ fluxes did not show substantial changes during the three FTCs, and the differences between watering and snow cover treatments were generally not significant, except for the first cycle (Table 2). Nevertheless, the dynamics of soil $\mathrm{N}_{2} \mathrm{O}$ fluxes during FTCs in the snow cover and watering treatments showed significant differences when the soil WFPS was around $50 \%(\mathrm{R} 3)$. In the watering 


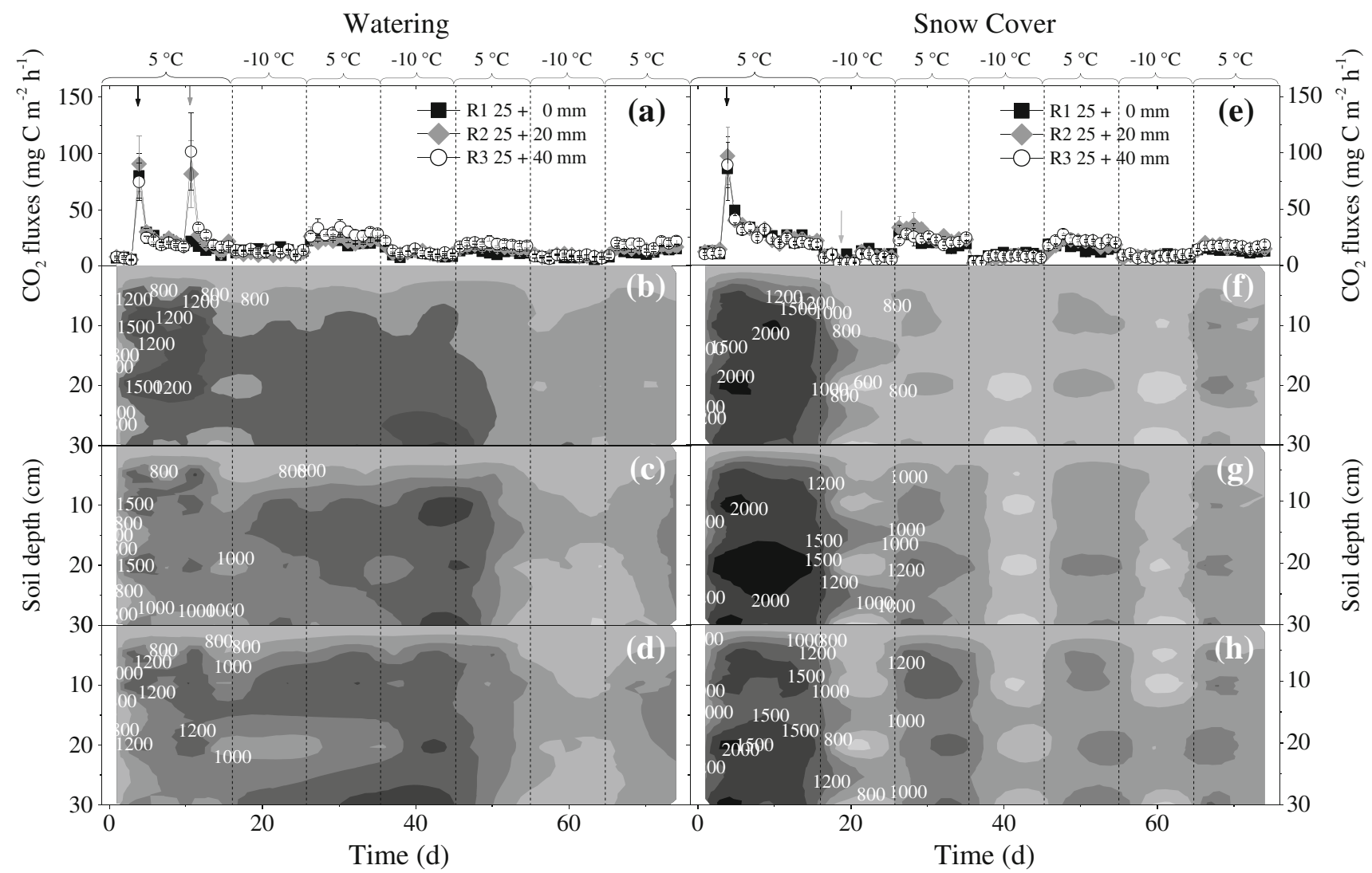

Fig. $1 \mathrm{CO}_{2}$ fluxes and dynamics of soil air $\mathrm{CO}_{2}$ concentrations along the soil profile $(0-30 \mathrm{~cm})$ of the undisturbed soil cores under different soil moisture and temperature conditions for watering $(\mathbf{a}-\mathbf{d})$ and snow cover (e-h) treatments. Vertical bars indicate standard errors of three spatial

replicates. Black arrows indicate the first watering; gray arrow indicates the second watering; light gray arrow marks the cover of snow. Soil air $\mathrm{CO}_{2}$ concentrations are in microliters per liter

treatment, enhanced $\mathrm{N}_{2} \mathrm{O}$ emissions were found during the first thawing period at soil moisture level R3, and the cumulative $\mathrm{N}_{2} \mathrm{O}$ fluxes significantly decreased during the following FTCs $(P<0.05$, Table 2$)$. In contrast, the $\mathrm{N}_{2} \mathrm{O}$ emission pulse during the first thawing period were relatively low in the snow cover treatment, while the strength of the $\mathrm{N}_{2} \mathrm{O}$ emission pulses increased during later thaw periods (Fig. 4e). The cumulative $\mathrm{N}_{2} \mathrm{O}$ fluxes during the entire three FTCs showed significant differences between watering and snow cover treatments $(P<$ 0.05 , Table 2). The two-way ANOVA analysis showed that FTCs and treatment exhibited significant effects on soil $\mathrm{N}_{2} \mathrm{O}$ fluxes at soil moisture levels R1 and R2, whereas their interaction had significant effect on $\mathrm{N}_{2} \mathrm{O}$ fluxes for all three soil moisture levels $(P<0.001$, Table 3$)$.

\section{Correlations between soil air concentrations and fluxes}

Highest soil $\mathrm{CO}_{2}$ concentrations were found during the dry-wet transition (watering treatment, $10 \mathrm{~cm}$ depth: $2,328 \mu \mathrm{L} \mathrm{L}^{-1}$; snow cover treatment, $20 \mathrm{~cm}$ depth: $3,741 \mu \mathrm{L} \mathrm{L}^{-1}$ ), whereas soil $\mathrm{CO}_{2}$ concentrations decreased significantly during soil frost (Fig. 1). At the onset of soil thawing, gradual increases of soil $\mathrm{CO}_{2}$ concentrations from the bottom to the top of soil profile were generally observed, which coincided with enhanced $\mathrm{CO}_{2}$ emissions. Significant positive correlations between $\mathrm{CO}_{2}$ fluxes and soil $\mathrm{CO}_{2}$ concentration differences between two sampling depths were observed for the upper $20 \mathrm{~cm}$ in snow cover treatment, whereas this correlation was only found at the topmost $5 \mathrm{~cm}$ soil depth in watering treatment $(P<0.001$, Table 4).

During most of the observation period, soil $\mathrm{CH}_{4}$ concentrations were found to decrease with depth, indicating that net $\mathrm{CH}_{4}$ consumption prevailed in most cases. Highest soil $\mathrm{CH}_{4}$ concentrations were generally observed during soil frost periods, whereas soil $\mathrm{CH}_{4}$ concentrations throughout the profiles declined strongly during the thawing periods (Fig. 3). However, no significant differences of soil $\mathrm{CH}_{4}$ concentrations were found among different soil moisture levels and between watering and snow cover treatments. In both watering and snow cover treatments, $\mathrm{CH}_{4}$ fluxes were significantly positively correlated with the soil gas concentration gradients in the upper $10 \mathrm{~cm}$ soil depth $(P<0.05$, Table 4).

Soil $\mathrm{N}_{2} \mathrm{O}$ concentrations increased substantially during the dry-wet transition, especially in the snow cover treatment. During the FTCs, $\mathrm{N}_{2} \mathrm{O}$ concentrations throughout the profiles 


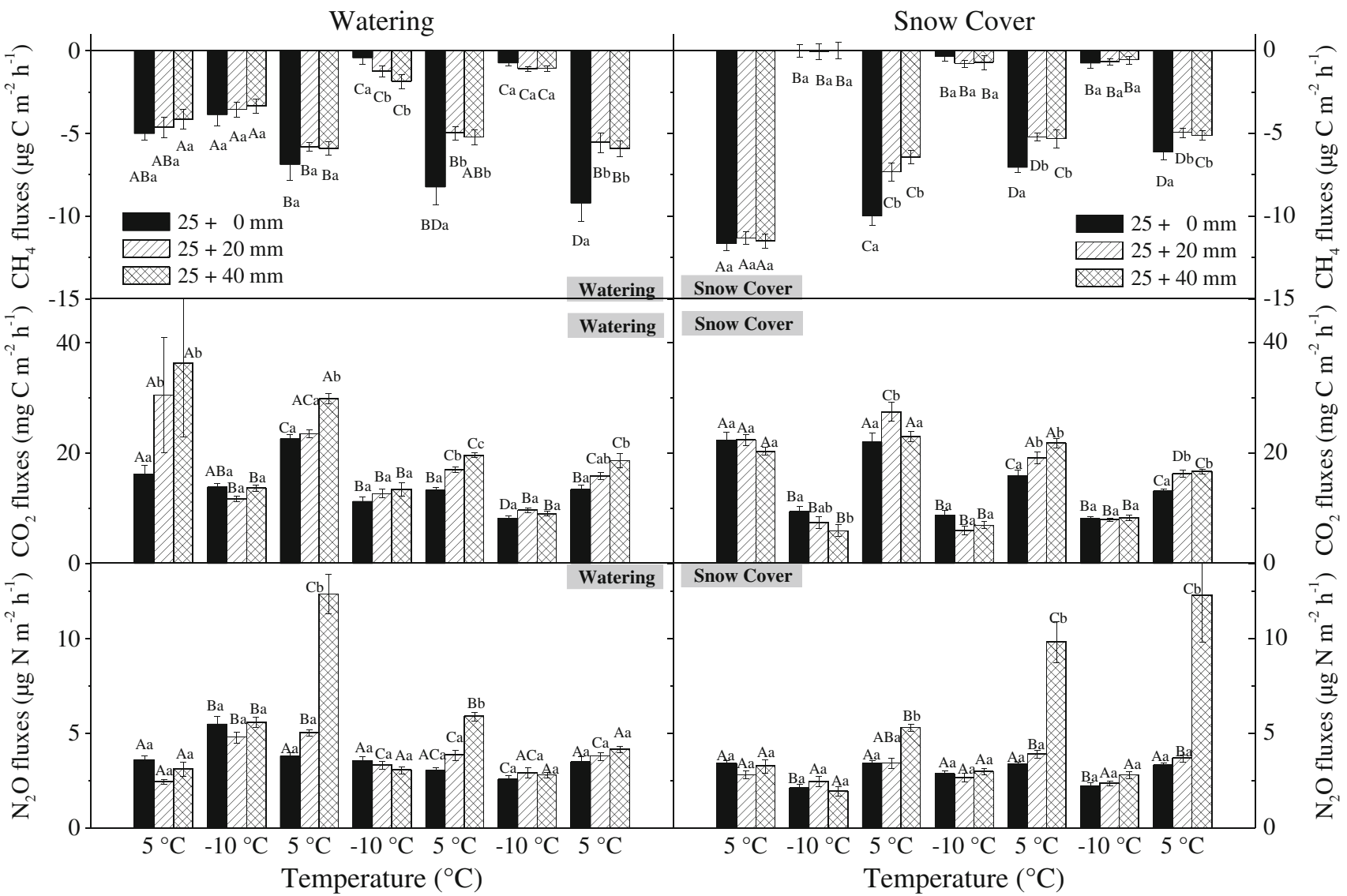

Fig. $2 \mathrm{CO}_{2}, \mathrm{CH}_{4}$, and $\mathrm{N}_{2} \mathrm{O}$ fluxes at different soil moisture and temperature levels for watering and snow cover treatments during incubation experiments. Uppercase letters indicate significant differences $(P<0.05)$

among different temperatures. Lowercase letters indicate significant differences $(P<0.05)$ among different soil moisture levels

of the R1 and R2 soils did not show significant changes. However, during soil thawing periods, $\mathrm{N}_{2} \mathrm{O}$ concentrations in the snow cover treatment at moisture level R3 increased steeply to values of up to $1,000 \mathrm{~nL} \mathrm{~L}^{-1}$, whereas such an increase was not found in the watering treatment (Fig. 4). These substantial increases of $\mathrm{N}_{2} \mathrm{O}$ concentrations along the soil profiles usually coincided with high rates of $\mathrm{N}_{2} \mathrm{O}$ emissions. Significant positive correlations between $\mathrm{N}_{2} \mathrm{O}$ emissions and soil $\mathrm{N}_{2} \mathrm{O}$ concentration

Table 2 Cumulative soil $\mathrm{CH}_{4}, \mathrm{CO}_{2}$, and $\mathrm{N}_{2} \mathrm{O}$ fluxes during the freeze-thaw cycles of different treatments

\begin{tabular}{|c|c|c|c|c|c|c|c|c|c|c|c|c|}
\hline \multirow[t]{2}{*}{ Treatment } & \multicolumn{4}{|c|}{ Cumulative $\mathrm{CH}_{4}$ flux $\left(\mathrm{mg} \mathrm{C} \mathrm{m}{ }^{-2}\right.$ ) } & \multicolumn{4}{|c|}{ Cumulative $\mathrm{CO}_{2}$ flux $\left(\mathrm{g} \mathrm{C} \mathrm{m}^{-2}\right)$} & \multicolumn{4}{|c|}{ Cumulative $\mathrm{N}_{2} \mathrm{O}$ flux ( $\mathrm{mg} \mathrm{N} \mathrm{m}^{-2}$ ) } \\
\hline & Cycle 1 & Cycle 2 & Cycle 3 & $\begin{array}{l}\text { Three } \\
\text { cycles }\end{array}$ & Cycle 1 & Cycle 2 & Cycle 3 & $\begin{array}{l}\text { Three } \\
\text { cycles }\end{array}$ & Cycle 1 & Cycle 2 & Cycle 3 & $\begin{array}{l}\text { Three } \\
\text { cycles }\end{array}$ \\
\hline \multicolumn{13}{|l|}{ Watering } \\
\hline $\mathrm{R} 1$ & $-2.56 \mathrm{Aa}$ & $-2.06 \mathrm{Ab}$ & $-2.37 \mathrm{Ab}$ & $-7.00 \mathrm{~A}$ & $8.72 \mathrm{ABa}$ & $5.86 \mathrm{ABab}$ & $5.17 \mathrm{Ab}$ & $19.75 \mathrm{~A}$ & $2.23 \mathrm{Aa}$ & $1.59 \mathrm{ABb}$ & $1.45 \mathrm{Ab}$ & $5.27 \mathrm{~A}$ \\
\hline $\mathrm{R} 2$ & $-2.24 \mathrm{Aa}$ & $-1.48 \mathrm{Ab}$ & $-1.59 \mathrm{Ab}$ & $-5.31 \mathrm{~A}$ & $8.45 \mathrm{ABa}$ & $7.13 \mathrm{ABa}$ & $6.12 \mathrm{Aa}$ & $21.70 \mathrm{AB}$ & $2.36 \mathrm{Aa}$ & $1.73 \mathrm{ABb}$ & $1.61 \mathrm{Ab}$ & $5.70 \mathrm{~A}$ \\
\hline $\mathrm{R} 3$ & $-2.22 \mathrm{Aa}$ & $-1.69 \mathrm{Ab}$ & $-1.67 \mathrm{Ab}$ & $-5.57 \mathrm{~A}$ & $10.44 \mathrm{Aa}$ & $7.92 \mathrm{Aab}$ & $6.63 \mathrm{Ab}$ & $24.99 \mathrm{~B}$ & $4.31 \mathrm{Ba}$ & $2.15 \mathrm{ABb}$ & $1.67 \mathrm{Ab}$ & $8.13 \mathrm{~B}$ \\
\hline \multicolumn{13}{|l|}{ Snow cover } \\
\hline $\mathrm{R} 1$ & $-2.39 \mathrm{Ba}$ & $-1.77 \mathrm{Ab}$ & $-1.65 \mathrm{Ab}$ & $-5.81 \mathrm{~A}$ & $7.53 \mathrm{ABa}$ & $5.90 \mathrm{ABa}$ & $5.08 \mathrm{Aa}$ & $18.51 \mathrm{~A}$ & $1.32 \mathrm{Ca}$ & $1.49 \mathrm{Aa}$ & $1.33 \mathrm{Aa}$ & $4.15 \mathrm{C}$ \\
\hline $\mathrm{R} 2$ & $-1.76 \mathrm{Ba}$ & $-1.43 \mathrm{Aa}$ & $-1.34 \mathrm{Aa}$ & $-4.54 \mathrm{~B}$ & $8.37 \mathrm{ABa}$ & $6.05 \mathrm{Ba}$ & $5.81 \mathrm{Aa}$ & $20.23 \mathrm{~A}$ & $1.42 \mathrm{Ca}$ & $1.58 \mathrm{Aa}$ & $1.46 \mathrm{Aa}$ & $4.45 \mathrm{C}$ \\
\hline $\mathrm{R} 3$ & $-1.53 \mathrm{Ba}$ & $-1.44 \mathrm{Aa}$ & $-1.36 \mathrm{Aa}$ & $-4.33 \mathrm{~B}$ & $6.97 \mathrm{Ba}$ & $6.90 \mathrm{ABa}$ & $5.98 \mathrm{Aa}$ & $19.85 \mathrm{~A}$ & $1.74 \mathrm{Ca}$ & $3.08 \mathrm{Bab}$ & $3.63 \mathrm{Bb}$ & $8.46 \mathrm{~A}$ \\
\hline
\end{tabular}

Uppercase letters indicate significant differences among different treatments; lowercase letters indicate significant differences among different freezethaw cycles $(P<0.05$, one-way ANOVA, LSD) 
Table 3 Results ( $P$ values) of two-way ANOVA on the effects of freeze-thaw cycles $(C)$, treatment $(T)$, and their interactions on soil $\mathrm{CH}_{4}, \mathrm{CO}_{2}$, and $\mathrm{N}_{2} \mathrm{O}$ fluxes under different soil moisture levels

\begin{tabular}{|c|c|c|c|c|c|c|c|c|c|}
\hline & \multicolumn{3}{|l|}{$\mathrm{R} 1$} & \multicolumn{3}{|l|}{$\mathrm{R} 2$} & \multicolumn{3}{|l|}{$\mathrm{R} 3$} \\
\hline & $\mathrm{CH}_{4}$ & $\mathrm{CO}_{2}$ & $\mathrm{~N}_{2} \mathrm{O}$ & $\mathrm{CH}_{4}$ & $\mathrm{CO}_{2}$ & $\mathrm{~N}_{2} \mathrm{O}$ & $\mathrm{CH}_{4}$ & $\mathrm{CO}_{2}$ & $\mathrm{~N}_{2} \mathrm{O}$ \\
\hline C & 0.417 & $<0.001$ & 0.001 & 0.095 & 0.002 & 0.001 & 0.392 & 0.008 & 0.574 \\
\hline$T$ & 0.282 & 0.316 & $<0.001$ & 0.273 & 0.401 & $<0.001$ & 0.077 & 0.006 & 0.768 \\
\hline$C \times T$ & 0.812 & 0.405 & $<0.001$ & 0.759 & 0.766 & $<0.001$ & 0.709 & 0.130 & $<0.001$ \\
\hline
\end{tabular}

differences between two sampling depths were observed for the upper $20 \mathrm{~cm}$ in the snow cover treatment $(P<0.001$, Table 4$)$, but in the watering treatment, significant correlations $(P<0.001)$ were only obtained for the topmost soil layer $(0-5 \mathrm{~cm})$.

\section{Soil characteristics}

After the incubation experiments, all soil cores were separated into four depth intervals for determination of soil $\mathrm{NO}_{3}{ }^{-}$ and $\mathrm{NH}_{4}{ }^{+}$concentrations, bulk density, WFPS, and microbial biomass $\mathrm{C}$ and $\mathrm{N}$ (Table 1). In both watering and snow cover treatments, bulk density increased with soil depth from values of approximately 1.2 to $1.5 \mathrm{~g} \mathrm{~cm}^{-3}$, whereas soil $\mathrm{NO}_{3}{ }^{-}$and
$\mathrm{NH}_{4}{ }^{+}$concentrations, WFPS, and microbial biomass $\mathrm{C}$ and $\mathrm{N}$ were generally significantly declining with soil depth. Soil WFPS values along the profile of moisture level R3 were significantly higher $(P<0.05)$ than those at level R1 in both treatments. ANOVA tests for soil inorganic N (only top 0 $15 \mathrm{~cm}$ soil) and microbial biomass $\mathrm{N}$ revealed significant differences between the watering and the snow cover treatment $(P<0.05)$, but statistically significant differences were not found for all other soil parameters. The significantly higher soil $\mathrm{NO}_{3}{ }^{-}-\mathrm{N}$ contents at the end of the experiments as compared to the values before incubation indicated that net $\mathrm{N}$ mineralization and nitrification was occurring in the soil cores.

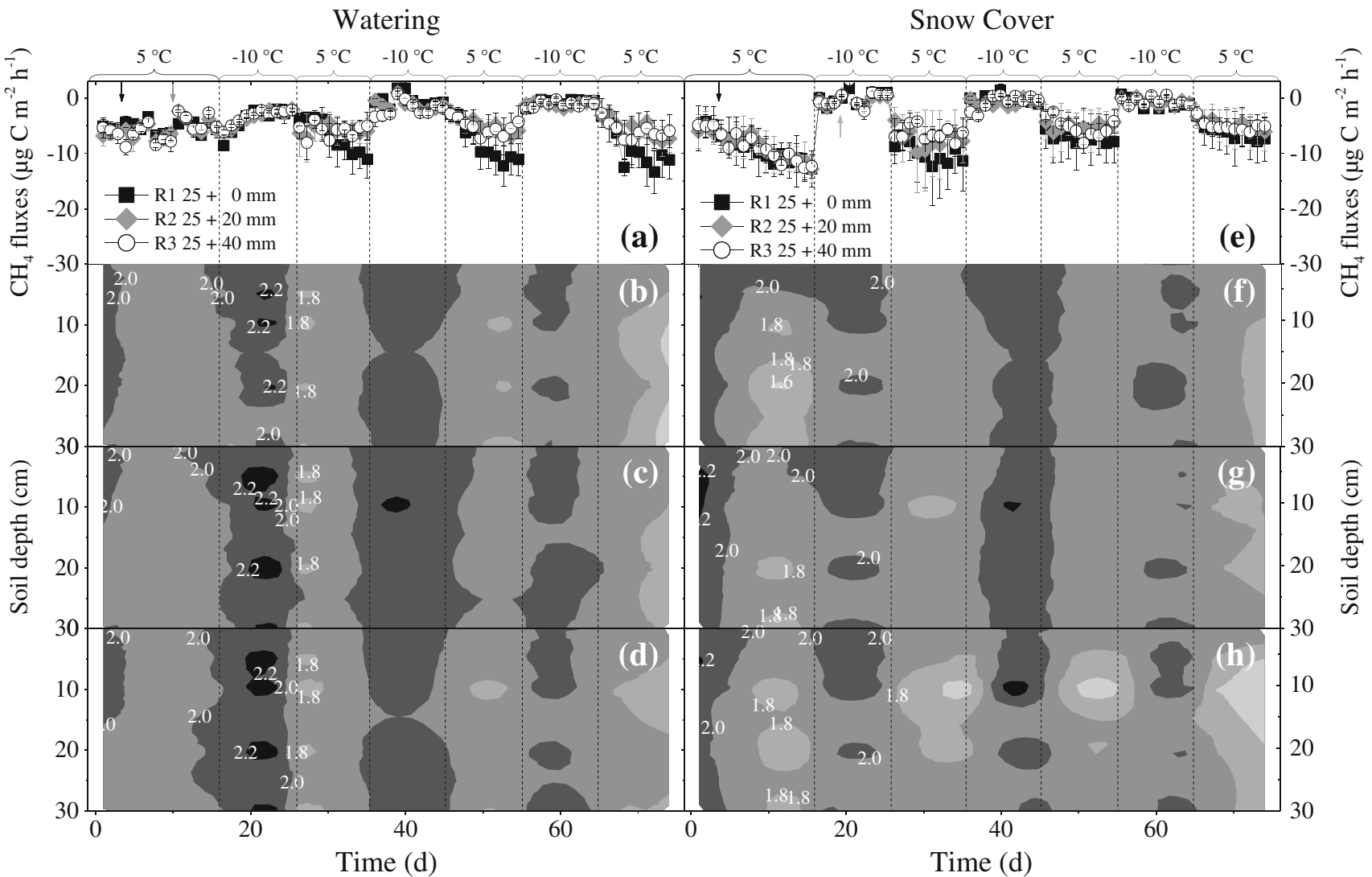

Fig. $3 \mathrm{CH}_{4}$ fluxes and dynamics of soil air $\mathrm{CH}_{4}$ concentrations along the soil profile $(0-30 \mathrm{~cm})$ of the undisturbed soil cores under different soil moisture and temperature conditions for watering (a-d) and snow cover (e-h) treatments. Vertical bars indicate standard errors of three spatial

replicates. Black arrows indicate the first watering; gray arrow indicates the second watering; light gray arrow marks the cover of snow. Soil air $\mathrm{CH}_{4}$ concentrations are in microliters per liter 


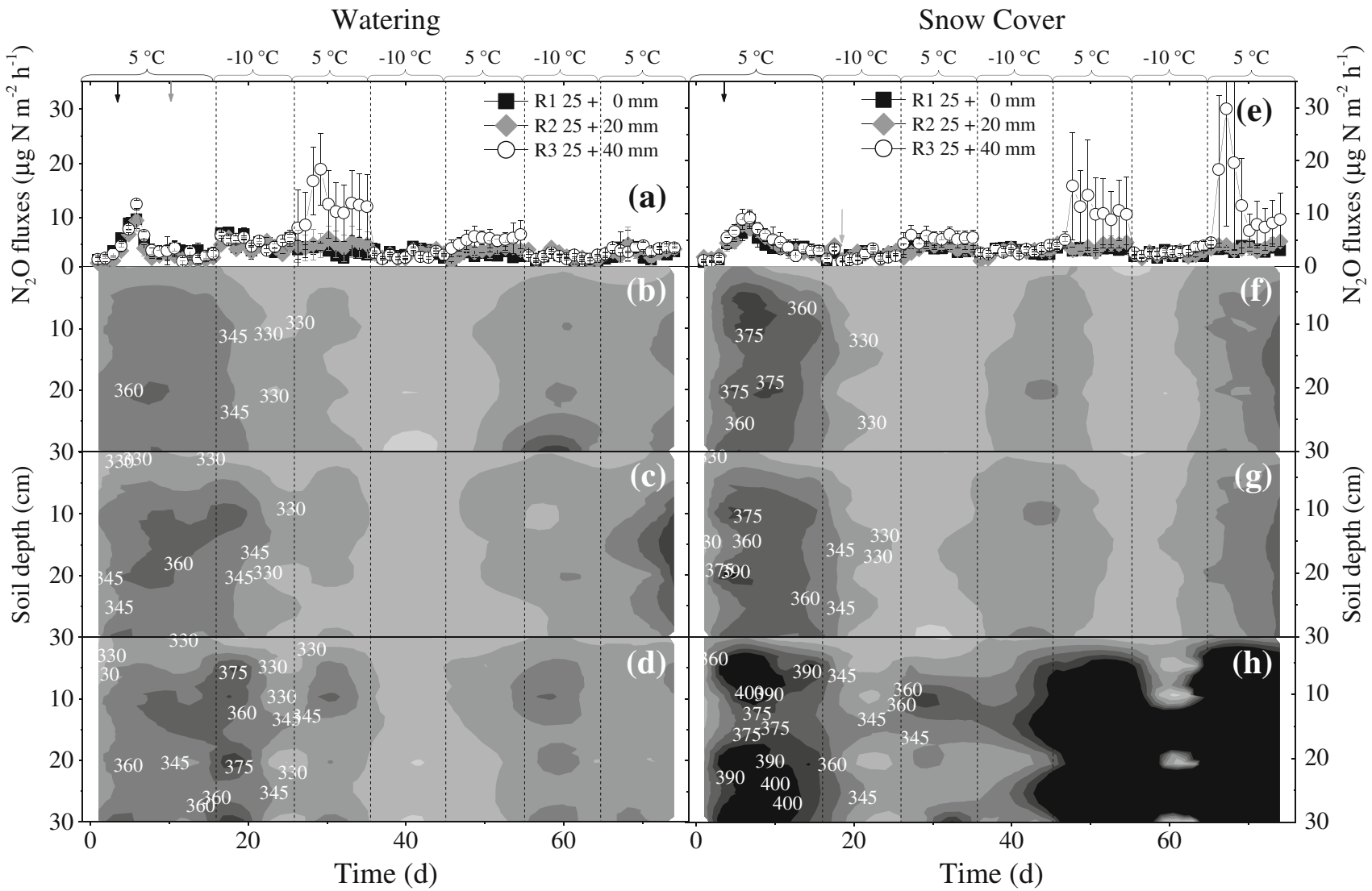

Fig. $4 \mathrm{~N}_{2} \mathrm{O}$ fluxes and dynamics of soil air $\mathrm{N}_{2} \mathrm{O}$ concentrations along the soil profile $(0-30 \mathrm{~cm})$ of the undisturbed soil cores under different soil moisture and temperature conditions for watering (a-d) and snow cover (e-h) treatments. Vertical bars indicate standard errors of three spatial

replicates. Black arrows indicate the first watering; gray arrow indicates the second watering; light gray arrow marks the addition of snow. Soil air $\mathrm{N}_{2} \mathrm{O}$ concentrations are in nanoliters per liter

\section{Discussion}

Effect of snow cover on gas fluxes during FTCs

In the present study, increased soil $\mathrm{CO}_{2}$ emissions during FTCs have been found in both watering and snow cover treatments, which is in agreement with previous observations in various ecosystems (Koponen and Martikainen 2004; Goldberg et al. 2008; Wu et al. 2010a, b; Kim et al. 2012). Stimulation of

microbial metabolisms by enhanced substrate supply and physical mechanisms have been commonly considered as the reasons for these emission pulses (Priemé and Christensen 2001; Matzner and Borken 2008; De Bruijn et al. 2009). In both watering and snow cover treatments, $\mathrm{CO}_{2}$ emissions were highest in the first thawing cycle and decreased in following cycles, indicating that repeated FTCs might have considerable effects on microbial activity/population and labile substrate pools (Priemé and Christensen 2001; Goldberg et al. 2008).

Table 4 Pearson coefficients $(R)$ of the correlation between $\mathrm{CH}_{4}, \mathrm{CO}_{2}$, and $\mathrm{N}_{2} \mathrm{O}$ fluxes and soil gas concentration differences between two sampling depths for different treatments $(N=78)$

\begin{tabular}{|c|c|c|c|c|c|c|}
\hline \multirow[t]{2}{*}{ Soil depths ${ }^{\mathrm{a}}$} & \multicolumn{3}{|l|}{ Watering } & \multicolumn{3}{|c|}{ Snow cover } \\
\hline & $\mathrm{CH}_{4}$ & $\mathrm{CO}_{2}$ & $\mathrm{~N}_{2} \mathrm{O}$ & $\mathrm{CH}_{4}$ & $\mathrm{CO}_{2}$ & $\mathrm{~N}_{2} \mathrm{O}$ \\
\hline $0-5 \mathrm{~cm}$ & $0.51 * *$ & $0.57 * *$ & $0.35^{* *}$ & $0.24 *$ & $0.77 * *$ & $0.73 * *$ \\
\hline $5-10 \mathrm{~cm}$ & $0.49 * *$ & 0.19 & 0.11 & $0.55^{* *}$ & $0.46^{* *}$ & $0.71 * *$ \\
\hline $10-20 \mathrm{~cm}$ & -0.05 & $-0.26^{*}$ & -0.15 & 0.08 & $0.43 * *$ & $0.37 * *$ \\
\hline $20-30 \mathrm{~cm}$ & 0.20 & $-0.29^{*}$ & -0.02 & $-0.28^{*}$ & $-0.44 * *$ & $0.27 *$ \\
\hline
\end{tabular}

$* P<0.05, * * P<0.001$ (significance levels)

${ }^{a}$ Soil gas concentration differences were calculated from the concentration of the lower sampling depth minus the concentration of the upper sampling depth 
Such a decrease of the initial $\mathrm{CO}_{2}$ emissions during repeated FTCs has not only been reported in laboratory studies (Priemé and Christensen 2001; Koponen and Martikainen 2004), but also in several field observations (Holst et al. 2008; Wu et al. 2010b), which suggests that adjusting soil moisture by watering before soil freezing might not lead to significant differences in the $\mathrm{CO}_{2}$ emission pattern during FTCs as compared to natural snow cover conditions. However, our results revealed that watering soil to a relatively high moisture level before freezing could induce significantly higher cumulative emissions of $\mathrm{CO}_{2}$ during multiple FTCs as compared to the snow cover treatment. This might partly be due to the relatively wetter topsoil in the snow cover treatment during the first thawing period, since higher soil water content could limit $\mathrm{O}_{2}$ diffusion into the soil and aerobic decomposition of organic C (Kiese and Butterbach-Bahl. 2002; Wu et al. 2010b).

In our study, soil $\mathrm{CH}_{4}$ fluxes were substantially reduced during frost periods, but significantly increased after thawing in both treatments, which is consistent with earlier studies (Ding and Cai 2007; Yu et al. 2007; Wu et al. 2010a). An incubation study with soils from various land use types by $\mathrm{Wu}$ et al. (2010a) revealed that soils consumed much less or even emitted $\mathrm{CH}_{4}$ during freezing. In addition to affecting microbial activity (Ding and Cai 2007), soil freezing may also limit the transport of gases by creating diffusion barriers (Borken et al. 2006; Wu et al. 2011). The enhanced $\mathrm{CH}_{4}$ consumption during thawing might be partly ascribed to increased methanotrophy and reduced methanogenesis at low temperatures (Ding and Cai 2007). Dunfield et al. (1993) also reported a negligible increase of $\mathrm{CH}_{4}$ production but a significant increase of $\mathrm{CH}_{4}$ consumption with a temperature increase from $0{ }^{\circ} \mathrm{C}$ to $15{ }^{\circ} \mathrm{C}$. However, other studies indicated that the saturated surface soils resulting from melting snow could favor $\mathrm{CH}_{4}$ production and suppress methanotrophy (Thauer 1998; Yu et al. 2007). Thus, further work is needed to reduce the associated uncertainties and identify the mechanisms and controls of $\mathrm{CH}_{4}$ production and consumption during soil FTCs.

Although enhanced $\mathrm{N}_{2} \mathrm{O}$ emissions were observed at soil moisture level R3 in both watering and snow cover treatments, the emission patterns were significantly different. In the watering treatment, the increased $\mathrm{N}_{2} \mathrm{O}$ emissions were highest during the first thawing cycle and decreased with successive cycles, which is in accordance with several incubations studies (Priemé and Christensen 2001; Koponen and Martikainen 2004). However, a repetition of the FTC resulted in an increase of $\mathrm{N}_{2} \mathrm{O}$ pulse emission during thawing in our snow cover treatment, which is in line with several field observations (Papen and Butterbach-Bahl 1999; Holst et al. 2008). In a long-term study with high temporal resolution using fully automated measuring systems, Wu et al. (2010b) found that a relative small $\mathrm{N}_{2} \mathrm{O}$ emission pulse was generally observed when the temperature first reached the freezing point and part of the snow cover started to melt. However, much higher emission peaks were observed in the following FTCs. In addition, Wu et al. (2010b) reported that freeze-thaw-related $\mathrm{CO}_{2}$ emissions usually occurred several days earlier than the $\mathrm{N}_{2} \mathrm{O}$ emission peaks, which was in good agreement with results of our snow cover treatment. This different time course of $\mathrm{CO}_{2}$ and $\mathrm{N}_{2} \mathrm{O}$ fluxes suggested that the $\mathrm{CO}_{2}$ peaks might partly be due to soil gas displacement, whereas the $\mathrm{N}_{2} \mathrm{O}$ emissions building up slowly over several days were mainly induced by a gradual depletion of soil oxygen that stimulates processes leading to $\mathrm{N}_{2} \mathrm{O}$ production during thawing. In a laboratory study, Goldberg et al. (2008) also found an increase of $\mathrm{N}_{2} \mathrm{O}$ emission peaks during repeated FTCs when soil columns were irrigated with an artificial throughfall solution after thawing instead of water addition before soil freezing.

Different soil water dynamics could be a reason for the contrasting $\mathrm{N}_{2} \mathrm{O}$ emission patterns of watering and snow cover treatments. For the watering treatment, the added water had already infiltrated into the soil before freezing. Soil aggregates could be disrupted as a result of ice crystals expanding in pores between particles during the first FTC, thereby increasing the amount of accessible substrate for $\mathrm{N}_{2} \mathrm{O}$ emissions (Priemé and Christensen 2001). In contrast, most of the supplied water was covering the soil surface as snow before thawing in the snow cover treatment. Thus, the soil water content in the snow cover treatment before freezing should be lower than that in the watering treatment, potentially resulting in less disruption of aggregates and microbial lysis. During the first thawing period, the snow started to melt and reduced soil aeration by creating water-saturated topsoil conditions, a process being discussed in detail by Wolf et al. (2012). However, Davidson (1991) indicated that $\mathrm{N}_{2} \mathrm{O}$ could be further transformed to $\mathrm{N}_{2}$ by denitrification at very moist conditions, resulting in an increased ratio of $\mathrm{N}_{2} / \mathrm{N}_{2} \mathrm{O}$. Therefore, the relatively small $\mathrm{N}_{2} \mathrm{O}$ emissions during the first thawing period in the snow cover treatment might be partly ascribed to less available substrate from disrupted soil aggregates and more moist topsoil conditions as compared to the watering treatment. With increasing amount of water from melting snow infiltrating into soil, the $\mathrm{N}_{2} \mathrm{O}$ emission response became stronger in the snow cover treatment, probably by increasing the amount of available substrate for denitrifiers by increasingly disrupting soil particles (Koponen and Martikainen 2004; Matzner and Borken 2008).

\section{Effect of soil moisture on gas fluxes during FTCs}

Very little is known about the effect of soil moisture on trace gas fluxes during FTCs, and the existing results are not consistent. By reviewing the literature, Matzner and Borken (2008) concluded that the increase of soil moisture at freezing could lead to increasing losses of $\mathrm{CO}_{2}$. However, Teepe et al. (2004) reported that the $\mathrm{CO}_{2}$ emissions decreased with increasing soil 
moisture in the range of $42-76 \%$ WFPS during cycles of freezing and thawing. Both in this and in earlier studies $(\mathrm{Wu}$ et al. 2010a), the $\mathrm{CO}_{2}$ emissions generally increased with increasing soil moisture in the range of 30-50\% WFPS, suggesting that increasing soil moisture up to medium levels might promote $\mathrm{CO}_{2}$ emissions during FTCs, while the initial $\mathrm{CO}_{2}$ pulse could be lower at high soil water content. Increased microbial activity and soil $\mathrm{C}$ mineralization might be the reasons for the enhanced $\mathrm{CO}_{2}$ emissions due to increased soil water content (Priemé and Christensen 2001; Zhou et al. 2012). While the maximum microbial respirations were assumed to occur at low to medium soil water content (Teepe et al. 2004; Holst et al. 2008), high soil WFPS values might advance oxygen deficiency by restricting diffusion and limit the activity of microbial only capable of aerobic respiration (Kiese and Butterbach-Bahl 2002).

The effect of soil moisture on $\mathrm{CH}_{4}$ fluxes during FTCs has not been clearly elucidated. In our study, soil $\mathrm{CH}_{4}$ uptake activity during thawing periods decreased with increasing soil water content, which might be due to hampered $\mathrm{CH}_{4}$ oxidation following the reduction of gas diffusion or increased soil methanogenic activity at higher soil moisture levels (Butterbach-Bahl and Papen 2002; Wu et al. 2011). Increases of freeze-thaw-related $\mathrm{N}_{2} \mathrm{O}$ fluxes with increasing soil WFPS have been reported in earlier publications (Koponen and Martikainen 2004; Wolf et al. 2010). Such an increase was also found in our study, e.g., $\mathrm{N}_{2} \mathrm{O}$ emissions at higher WFPS values $(\sim 50 \%)$ were significantly greater than those at lower soil water contents. However, we did not observe significant $\mathrm{N}_{2} \mathrm{O}$ emissions during FTCs when the soil WFPS were relatively low (30-40\%). An incubation study by Yao et al. (2010), who sampled soil cores from the same region as our study, also showed that soils with low WFPS could not generate substantial $\mathrm{N}_{2} \mathrm{O}$ emissions during the thawing period. Moreover, by conducting year-round field measurements of $\mathrm{N}_{2} \mathrm{O}$ in an alpine grassland, Li et al. (2012) supposed that low soil moisture could be one of the reasons for the non-significant $\mathrm{N}_{2} \mathrm{O}$ emissions during spring thaw. Therefore, a threshold value of soil moisture might exist to trigger $\mathrm{N}_{2} \mathrm{O}$ peaks during thawing, but the values for various soils and the internal mechanisms need further research.

\section{Correlations between soil air concentrations and fluxes}

Measurements of soil air concentration have been commonly used to estimate soil surface fluxes (Pihlatie et al. 2007; Kusa et al. 2008; Wolf et al. 2011), whereas only a few studies are available during freezing and thawing periods (Regina et al. 2004; Goldberg et al. 2010; Yanai et al. 2011). Soil $\mathrm{CO}_{2}$ and $\mathrm{N}_{2} \mathrm{O}$ concentrations declined sharply during most freezing periods in our study, suggesting a decrease of microbial activity during freezing. However, the increase of $\mathrm{CH}_{4}$ concentrations throughout the soil profile during freezing periods indicates that freezing of soil pore water reduced $\mathrm{O}_{2}$ and $\mathrm{CH}_{4}$ diffusion and shifted the balance between $\mathrm{CH}_{4}$ oxidation and production towards the production side, especially in the deeper soil layers (Wu et al. 2010a). Significant positive correlations between $\mathrm{CH}_{4}$ fluxes and soil $\mathrm{CH}_{4}$ concentration gradients in the upper $10-\mathrm{cm}$ depth in both watering and snow cover treatments indicated that methane oxidation is strongest in the upper soil layers, which is in accordance with previous findings (Butterbach-Bahl and Papen 2002; Wu et al. 2010a). In snow cover treatment, $\mathrm{CO}_{2}$ and $\mathrm{N}_{2} \mathrm{O}$ fluxes were significantly positively correlated with the soil gas concentration gradients in the upper 20-cm soil depth, whereas the $\mathrm{CO}_{2}$ and $\mathrm{N}_{2} \mathrm{O}$ emissions in watering treatment were mainly derived from the topmost soil layer $(0-5 \mathrm{~cm})$. These differences suggest that establish soil moisture in dissimilar ways might lead to different $\mathrm{N}$ and $\mathrm{C}$ turnover rates along the soil profile. Moreover, the nonsignificant $\mathrm{N}_{2} \mathrm{O}$ emissions during FTCs at the two lower soil moisture levels ( $\mathrm{R} 1$ and $\mathrm{R} 2$ ) was reflected by the tiny changes of soil $\mathrm{N}_{2} \mathrm{O}$ concentrations throughout the profile at the same time. Although soil air concentration measurement could not serve as an adequate stand-alone substitute for flux measurements (Wolf et al. 2011), they can provide additional information on the $\mathrm{N}$ and $\mathrm{C}$ turnover process dynamics along the soil profile as shown by this study.

\section{Conclusions}

Our results clearly show that it is of importance for soil GHG fluxes during freeze-thaw periods how changes in soil moisture are established. If the different soil moisture levels were established before soil freezing, in our study by watering, pulse emissions of $\mathrm{N}_{2} \mathrm{O}$ were highest in the first FTC and declined thereafter. If changes in soil moisture were created by adding snow on frozen soil, the intensity of freeze-thaw $\mathrm{N}_{2} \mathrm{O}$ emission pulses increased with the number of freezing cycles. This might be partly due to the different soil water dynamics. In addition, adjusting soil moisture by watering before soil freezing might induce significant differences in the cumulative fluxes of $\mathrm{CH}_{4}$, $\mathrm{CO}_{2}$, and $\mathrm{N}_{2} \mathrm{O}$ during FTCs as compared to the snow cover treatment, especially at relatively high soil moisture levels. Furthermore, our study indicates that a critical threshold value of soil moisture needs to be reached before significant $\mathrm{N}_{2} \mathrm{O}$ emission pulses during soil thawing can be observed. In our study, only at highest soil moisture values of approximately $50 \%$ WFPS $\mathrm{N}_{2} \mathrm{O}$ emission pulses did occur. Thus, the effects of snow cover and soil moisture on $\mathrm{C}$ and $\mathrm{N}$ trace gases fluxes during FTCs, as well as the underlying processes and mechanisms, should be considered in future studies.

Acknowledgements This study was supported by the National Natural Science Foundation of China (41105117), the Strategic Priority Research Program of the Chinese Academy of Sciences (XDA05060103), and 
State Key Laboratory of Forest and Soil Ecology (LFSE2013-06). One of the authors, Xing $\mathrm{Wu}$, would like to thank the Helmholtz Association of German Research Centers and the China Scholarship Council (CSC) for providing financial support within the Junior Scientists Exchange Program. Special thanks go to Regina Wiegel and Wang Changhui for the microbial biomass $\mathrm{C}$ and $\mathrm{N}$ measurements and Prof. P. Nannipieri, Editorin-Chief, and two reviewers for constructive comments on the early version of the manuscript.

\section{References}

Borken W, Davidson EA, Savage K, Sundquist ET, Steudler P (2006) Effect of summer throughfall exclusion, summer drought, and winter snow cover on methane fluxes in a temperate forest soil. Soil Biol Biochem 38:1388-1395

Breuer L, Kiese R, Butterbach-Bahl K (2002) Temperature and moisture effects on nitrification rates in tropical rain-forest soils. Soil Sci Soc Am J 66:834-844

Buckeridge KM, Grogan P (2010) Deepened snow increases late thaw biogeochemical pulses in mesic low arctic tundra. Biogeochemistry 101:105-121

Butterbach-Bahl K, Papen H (2002) Four years continuous record of $\mathrm{CH}_{4}$-exchange between the atmosphere and untreated and limed soil of a N-saturated spruce and beech forest ecosystem in Germany. Plant Soil 240:77-90

Davidson EA (1991) Fluxes of nitrous oxide and nitric oxide form terrestrial ecosystems. In: Rogers JE, Whitman WB (eds) Microbial production and consumption of greenhouse gases: methane, nitrogen oxides, and halomethanes. American Society for Microbiology, Washington, pp 219-235

De Bruijn AMG, Butterbach-Bahl K, Blagodatsky S, Grote R (2009) Model evaluation of different mechanisms driving freeze-thaw $\mathrm{N}_{2} \mathrm{O}$ emissions. Agric Ecosyst Environ 133:196-207

Ding WX, Cai ZC (2007) Methane emission from natural wetlands in China: summary of years 1995-2004 studies. Pedosphere 17:475486

Dunfield P, Knowles R, Dumont R, Moore TR (1993) Methane production and consumption in temperate and subarctic peat soils: response to temperature and $\mathrm{pH}$. Soil Biol Biochem 25:321-326

Feng XJ, Nielsen LL, Simpson MJ (2007) Responses of soil organic matter and microorganisms to freeze-thaw cycles. Soil Biol Biochem 39:2027-2037

Goldberg SD, Muhr J, Borken W, Gebauer G (2008) Fluxes of climaterelevant trace gases between a Norway spruce forest soil and atmosphere during repeated freeze-thaw cycles in mesocosms. J Plant Nutr Soil Sci 171:729-739

Goldberg SD, Borken W, Gebauer G (2010) $\mathrm{N}_{2} \mathrm{O}$ emission in a Norway spruce forest due to soil frost: concentration and isotope profiles shed a new light on an old story. Biogeochemistry 97:21-30

Groffman PM, Hardy JP, Driscoll CT, Fahey TJ (2006) Snow depth, soil freezing, and fluxes of carbon dioxide, nitrous oxide and methane in a northern hardwood forest. Global Change Biol 12:1748-1760

Groffman PM, Hardy JP, Fashu-Kanu S, Driscoll CT, Cleavitt NL, Fahey TJ, Fisk MC (2011) Snow depth, soil freezing and nitrogen cycling in a northern hardwood forest landscape. Biogeochemistry 102: 223-238

Henry HAL (2007) Soil freeze-thaw cycle experiments: trends, methodological weaknesses and suggested improvements. Soil Biol Biochem 39:977-986

Holst J, Liu C, Yao Z, Brüggemann N, Zheng X, Giese M, ButterbachBahl K (2008) Fluxes of nitrous oxide, methane and carbon dioxide during freezing-thawing cycles in an Inner Mongolian steppe. Plant Soil 308:105-117
Kern J, Hellebrand HJ, Gömmel M, Ammon C, Berg W (2012) Effects of climatic factors and soil management on the methane flux in soils from annual and perennial energy crops. Biol Fertil Soils 48:1-8

Kiese R, Butterbach-Bahl K (2002) $\mathrm{N}_{2} \mathrm{O}$ and $\mathrm{CO}_{2}$ emissions from three different tropical forest sites in the wet tropics of Queensland, Australia. Soil Biol Biochem 34:975-987

Kim DG, Vargas R, Bond-Lamberty B, Turetsky MR (2012) Effects of soil rewetting and thawing on soil gas fluxes: a review of current literature and suggestions for future research. Biogeosciences 9: 2459-2483

Koponen HT, Martikainen PJ (2004) Soil water content and freezing temperature affect freeze-thaw related $\mathrm{N}_{2} \mathrm{O}$ production in organic soil. Nutr Cycl Agroecosyst 69:213-219

Kusa K, Sawamoto T, Hu R, Hatano R (2008) Comparison of the closedchamber and gas concentration gradient methods for measurement of $\mathrm{CO}_{2}$ and $\mathrm{N}_{2} \mathrm{O}$ fluxes in two upland field soils. Soil Sci Plant Nutr 54:777-785

Li K, Gong Y, Song W, Lv J, Chang Y, Hu Y, Tian C, Christie P, Liu X (2012) No significant nitrous oxide emissions during spring thaw under grazing and nitrogen addition in an alpine grassland. Global Change Biol 18:2546-2554

Ludwig B, Wolf I, Teepe R (2004) Contribution of nitrification and denitrification to the emission of $\mathrm{N}_{2} \mathrm{O}$ in a freeze-thaw event in an agricultural soil. J Plant Nutr Soil Sci 167:678-684

Matzner E, Borken W (2008) Do freeze-thaw events enhance C and N losses from soils of different ecosystems? A review. Eur J Soil Sci 59:274-284

Papen H, Butterbach-Bahl K (1999) A 3-year continuous record of nitrogen trace gas fluxes from untreated and limed soil of a Nsaturated spruce and beech forest ecosystem in Germany: $1 . \mathrm{N}_{2} \mathrm{O}$ emissions. J Geophys Res 104:18487-18503

Pihlatie M, Pumpanen J, Rinne J, Ilvesniemi H, Simojoki A, Hari P, Vesala T (2007) Gas concentration driven fluxes of nitrous oxide and carbon dioxide in boreal forest soil. Tellus B 59:458-469

Priemé A, Christensen S (2001) Natural perturbations, drying-wetting and freezing-thawing cycles, and the emission of nitrous oxide, carbon dioxide and methane from farmed organic soils. Soil Biol Biochem 33:2083-2091

Regina K, Syväsolo E, Hannukkala A, Esala M (2004) Fluxes of $\mathrm{N}_{2} \mathrm{O}$ from farmed peat soils in Finland. Eur J Soil Sci 55:591-599

Schindlbacher A, Zechmeister-Boltenstern S, Butterbach-Bahl K (2004) Effects of soil moisture and temperature on $\mathrm{NO}, \mathrm{NO}_{2}$, and $\mathrm{N}_{2} \mathrm{O}$ emissions from European forest soils. J Geophys Res 109, D17302

Teepe R, Brumme R, Beese F (2001) Nitrous oxide emissions from soil during freezing and thawing periods. Soil Biol Biochem 33:12691275

Teepe R, Vor A, Beese F, Ludwig B (2004) Emissions of $\mathrm{N}_{2} \mathrm{O}$ from soils during cycles of freezing and thawing and the effects of soil water, texture and duration of freezing. Eur J Soil Sci 55:357-365

Thauer R (1998) Biochemistry of methanogenesis: a tribute to Marjory Stephenson. Microbiology 144:2377-2406

Vance ED, Brookes PC, Jenkinson DS (1987) Microbial biomass measurements in forest soils: determination of $k_{c}$ values and tests of hypothesis to explain the failure of the chloroform fumigationincubation method in acid soils. Soil Biol Biochem 19:689-696

Wolf B, Zheng X, Brüggemann N, Chen W, Dannenmann M, Han X, Sutton MA, Wu H, Yao Z, Butterbach-Bahl K (2010) Grazinginduced reduction of natural nitrous oxide release from continental steppe. Nature 464:881-884

Wolf B, Chen W, Brüggemann N, Zheng X, Pumpanen J, ButterbachBahl K (2011) Applicability of the soil gradient method for estimating soil-atmosphere $\mathrm{CO}_{2}, \mathrm{CH}_{4}$, and $\mathrm{N}_{2} \mathrm{O}$ fluxes for steppe soils in Inner Mongolia. J Plant Nutr Soil Sci 174:359-372

Wolf B, Kiese R, Chen W, Grote R, Butterbach-Bahl K (2012) Modeling $\mathrm{N}_{2} \mathrm{O}$ emissions from steppe in Inner Mongolia, China, with consideration of spring thaw and grazing intensity. Plant Soil 350:297-310 
Wu X, Yao Z, Brüggemann N, Shen ZY, Wolf B, Dannenmann M, Zheng X, Butterbach-Bahl K (2010a) Effects of soil moisture and temperature on $\mathrm{CO}_{2}$ and $\mathrm{CH}_{4}$ soil-atmosphere exchange of various land use/cover types in a semi-arid grassland in Inner Mongolia, China. Soil Biol Biochem 42:773-787

Wu X, Brüggemann N, Gasche R, Shen ZY, Wolf B, Butterbach-Bahl K (2010b) Environmental controls over soil-atmosphere exchange of $\mathrm{N}_{2} \mathrm{O}$, NO and $\mathrm{CO}_{2}$ in a temperate Norway spruce forest. Global Biogeochem Cycles 24, GB2012

Wu X, Brüggemann N, Gasche R, Papen H, Willibald G, ButterbachBahl K (2011) Long-term effects of clear-cutting and selective cutting on soil methane fluxes in a temperate spruce forest in southern Germany. Environ Pollut 159:2467-2475

Yanai Y, Hirota T, Iwata Y, Nemoto M, Nagata O, Koga N (2011) Accumulation of nitrous oxide and depletion of oxygen in seasonally frozen soils in northern Japan - snow cover manipulation experiments. Soil Biol Biochem 43:1779-1786

Yao Z, Wu X, Wolf B, Dannenmann M, Butterbach-Bahl K, Brüggemann N, Chen W, Zheng X (2010) Soil-atmosphere exchange potential of $\mathrm{NO}$ and $\mathrm{N}_{2} \mathrm{O}$ in different land use types of Inner Mongolia as affected by soil temperature, soil moisture, freeze-thaw, and drying-wetting events. J Geophys Res 115, D17116

Yu J, Sun W, Liu J, Wang J, Yang J, Meixner FX (2007) Enhanced net formations of nitrous oxide and methane underneath the frozen soil in Sanjiang wetland, northeastern China. J Geophys Res 112, D07111

Zhou X, Chen C, Wang Y, Xu Z, Hu Z, Cui X, Hao Y (2012) Effects of warming and increased precipitation on soil carbon mineralization in an Inner Mongolian grassland after 6 years of treatments. Biol Fertil Soils 48:859-866 